\title{
LACK OF PARALLELISM BETWEEN THE POSITIVE INOTROPIC EFFECTS OF VARIOUS CARDIAC STIMULANTS AND THEIR ACTIVITIES TO PRODUCE THE SLOW CHANNELS IN THE DEPOLARIZED MYOCARDIUM
}

\author{
Hideko TATSUNO-ATODA*, Koki SHIGENOBU and Yutaka KASUYA \\ Department of Chemical Pharmacology, Faculty of Pharmaceutical Sciences, \\ The University of Tokyo, Bunkyo-ku, Tokyo 113, Japan
}

Accepted August 11, 1980

\begin{abstract}
Positive inotropic actions in the normal guinea pig cardiac muscle and the activities required to produce electrical and mechanical responses in the depolarized muscle were examined using epinephrine. dopamine, metanephrine, aminophylline, histamine, serotonin, tyramine. tetraethylammonium (TEA), tetramethylammonium (TMA), and X-537A, a calcium ionophore. In the normal cardiac muscle, histamine produced the greatest positive inotropic action, followed by epinephrine, dopamine and TEA. In the cardiac muscle made inexcitable by the elevated potassium (30 mM), all of the agents tested produced electrical and mechanical responses. Aminophylline was the most potent in the activity to produce the mechanical response in the depolarized muscle; the potencies of histamine, dopamine, X-537A, epinephrine and TEA were much the same. From these results, it was concluded that the positive inotropic effects of the cardiac stimulants are not produced solely through the mechanisms related to the slow channels, but that other mechanisms must be involved in the normal condition where the fast sodium channels are functioning.
\end{abstract}

It is generally accepted that the force of the muscle contraction is dependent on the intracellular free ionized calcium. Calcium ions for the muscle contraction are either those released from the intracellular store sites or those inflowing through the cell membrane from outside the cell; or, the latter calcium ions may produce the release of the calcium ions from the intracellular store sites. In cardiac muscle, it is considered that the calcium inflow through the cell membrane makes a great contribution to the muscular contraction. The well established slow

\footnotetext{
* Present address: Meiji College of Pharmacy,
} Tanashi, Tokyo 188, Japan channel system (1-3) which transmits predominantly calcium ions through the cell membrane (calcium current channels) may be an important, or presumably predominant. pathway for this calcium inflow.

One of the present authors has reported that catecholamines produced calcium current channels in chick embryonic hearts in which the fast.sodium channels were blocked by tetrodotoxin or elevated external potassium (4); slow electrical responses were produced with concomitant contractions. It was later confirmed that these types of electrical and mechanical responses were produced similarly in the perfused guinea pig heart and it was proposed that this channel may be slow 
$\mathrm{Ca}^{2+}-\mathrm{Na}^{+}$type $(5,6)$. This type of response is a simple and useful method to test whether an agent can increase the density of the slow calcium or $\mathrm{Ca}^{2+}-\mathrm{Na}^{+}$channels (7-9).

Positive inotropic agents are expected to increase more or less the calcium inflow by increasing the density of the slow channels. In fact, some of the inotropic agents including catecholamines have been shown to increase the density of the slow channels as described above. However, systematic studies using various inotropic agents have apparently not been documented. We investigated the possible relations between the positive inotropic effects of various agents and their abilities to produce the slow electrical and mechanical responses in the myocardial preparations in which the fast $\mathrm{Na}$ channels are inactivated by the elevated external potassium.

Inotropic agents tested were catecholamines (epinephrine, dopamine), histamine, serotonin, tyramine, tetraethylammonium (TEA), tetramethylammonium (TMA), and a calcium ionophore antibiotic $X-537 \mathrm{~A}$.

\section{MATERIALS AND METHODS}

Male guinea pigs were killed by a blow on the head and the hearts were excised. For the mechanical experiments, papillary muscle preparations were suspended vertically in the organ bath containing $30 \mathrm{ml}$ of the physiological salt solution (PSS) of the following composition (mM): $\mathrm{NaCl} 135$, $\mathrm{KCl} 3, \mathrm{CaCl}_{2} 2, \mathrm{MgCl}_{2} 1, \mathrm{NaHCO}_{3} 15$ and glucose 5.5. Bathing solution was bubbled with oxygen-mixture $\left(\begin{array}{llll}95 \% & \mathrm{O}_{2}-5 \% & \mathrm{CO}_{2}\end{array}\right)$ at $37^{\circ} \mathrm{C}$. Contractions were measured with a force displacement transducer (Nihon Kohden. Model SB-1T) and recorded on an ink-writing oscillograph (Nihon Kohden, Model RM-150). Electrical field stimulation of $5 \mathrm{msec}$ duration was applied through bipolar platinum plate electrodes $(5 \times 20 \mathrm{~mm})$ at a frequency of $3 \mathrm{~Hz}$; at this frequency, the maximum contractile force was obtained in control condition. For the electrical experiments, papillary muscles were horizontally pinned down on the paraffin block placed in a $30 \mathrm{ml}$ organ bath containing the PSS of the same composition as above and circulating with the bubbled oxygen-mixture. Conventional microelectrode studies were done using glass microelectrodes filled with $3 \mathrm{M} \mathrm{KCl}$. Electrical responses were displayed on a dual beam cathode ray oscilloscope (Nihon Kohden, Model VC-6) after passing a microelectrode preamplifier with capacity neutralization (Nihon Kohden, Model MZ-3).

Reserpinization was carried out by giving reserpine at a dose of $5 \mathrm{mg} / \mathrm{kg}$ i.p. one day before the experiments.

\section{RESULTS}

Positive inotropism: Positive inotropic actions of the agents were tested with the electrically driven $(5 \mathrm{msec}, 3 \mathrm{~Hz}$, supramaximal) papillary muscles suspended in the normal PSS $\left(\left[\mathrm{K}^{+}\right]_{0}=3 \mathrm{mM}\right.$, see Methods). As shown in Fig. 1, all of the agents tested showed the positive inotropic action, the most potent being histamine. Histamine produced a significant increase in the contraction at the concentrations as low as $3 \times 10^{-7} \mathrm{M}$. Increase in the contractile force by $67.4 \pm 11.0 \%$ was obtained with histamine at the concentration of $3 \times 10^{-5} \mathrm{M}$ which was the highest concentration of histamine without producing the arrhythmia (ventricular automaticity). Epinephrine and dopamine showed the positive inotropic action at the concentrations higher than $10^{-6} \mathrm{M}$; the increases in the contractile force produced by $3 \times 10^{-5} \mathrm{M}$ of these agents were $45.9 \pm 8.4 \%$ and $31.6 \pm 9.4 \%$, respectively.

Tyramine produced the positive inotropic action at the concentrations over $3 \times 10^{-7} \mathrm{M}$, and the maximum increase in the contractile force $(28.3 \pm 4.6 \%)$ was achieved at the concentration of $10^{-4} \mathrm{M}$. Positive inotropic 


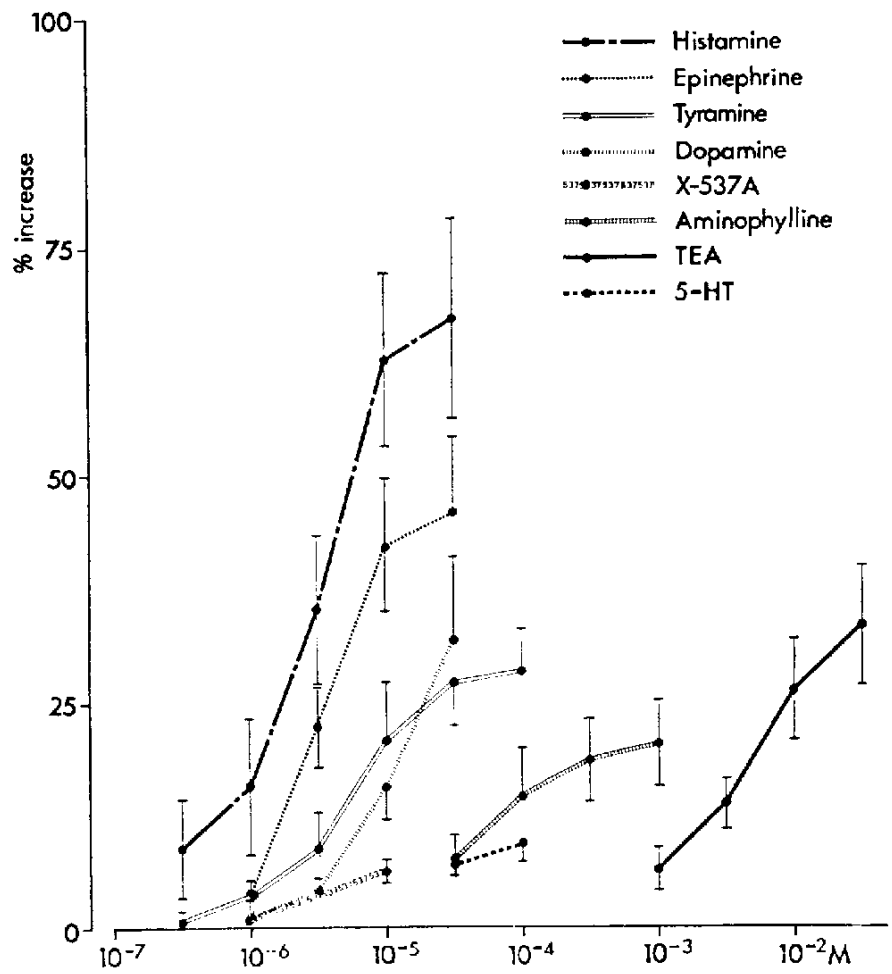

Fig. 1. Dose-response curves for positive inotropic effects of the agents tested in the electrically driven guinea pig papillary muscle. Ordinate: increase in the contractile force as expressed by the percent of the control contractile force before the drug addition (537 mg $\pm 29 \mathrm{mg}$ ). Abscissa: molar concentrations of the agents. Vertical bars are \pm S.E.M. ( 6 experiments for each drug).

actions of aminophylline and TEA were produced only at high concentrations: concentrations over $3 \times 10^{-5} \mathrm{M}$ for aminophylline and $10^{-3} \mathrm{M}$ for TEA. $10^{-3} \mathrm{M}$ aminophylline produced an increase in contractile force by $20.4 \pm 4.8 \%$ and $3 \times 10^{-2} \mathrm{M}$ TEA by $33.4 \pm 1.5 \%$. A calcium ionophore, $X-537 \mathrm{~A}$, produced an increase in contractile force by $6.2 \pm 1.49 \%$ at the concentration of $10^{-5} \mathrm{M}$. In this case, the papillary muscles from the reserpinized guinea pigs were used since this agent was reported to induce a release of the endogenous catecholamines. The positive inotropic action of serotonin (5-HT) was slight; $3 \times 10^{-5} \mathrm{M}$ produced an increase in contractile force by $7.0 \pm 1.21 \%$ and $10^{-4} \mathrm{M}$ by $9.4 \pm 2.05 \%$. The positive inotropic action of metanephrine $\left(3 \times 10^{-4} \mathrm{M}\right)$ was also slight: precise measurements of the increase in the contractile force by metanephrine were not feasible since this compound produced ventricular automaticity.

Induction of electrical and mechanical responses in the myocardium made inexcitable by the elevated potassium: In normal PSS $\left(\left[\mathrm{K}^{+}\right]_{0}=3 \mathrm{mM}\right)$, action potentials with a normal appearance with the fast rate of rise were recorded. When the bathing solution was replaced with the high potassium solution $\left(\left[\mathrm{K}^{+}\right]_{0}=30 \mathrm{mM}\right)$, the membrane depolarized immediately to about $-40 \mathrm{mV}$. and the action potentials could not be produced even with stimulation of a 10 -fold higher intensity than the normal. After confirming the loss of excitability due to the inactivation of the fast sodium channels, the 
agents were added at the concentrations of $80-100 \%$ of those which produced the maximum inotropic effects in the normal condition. All agonists tested produced the slow but overshooting action potentials; some of the representative slow responses are shown in Fig. 2. Simultaneously, these agents produced vigorous contractions which could be visually observed under the dissecting microscope.

The rate of rise and the overshoot of these slow responses were dependent upon the external calcium concentrations. The addition of EGTA to chelate the $\left[\mathrm{Ca}^{2+}\right]_{0}, \mathrm{Mn}^{2+}$, or verapamil suppressed or abolished the slow response. These results are in good accordance with findings already reported (4, 8-10).

When the bathing solution was replaced with the high potassium solution $\left(\left[\mathrm{K}^{+}\right]_{0}=30\right.$ $\mathrm{mM})$. the mechanical response disappeared almost completely, and stimulation, the intensity of which was about 10 -fold greater than normal produced no mechanical

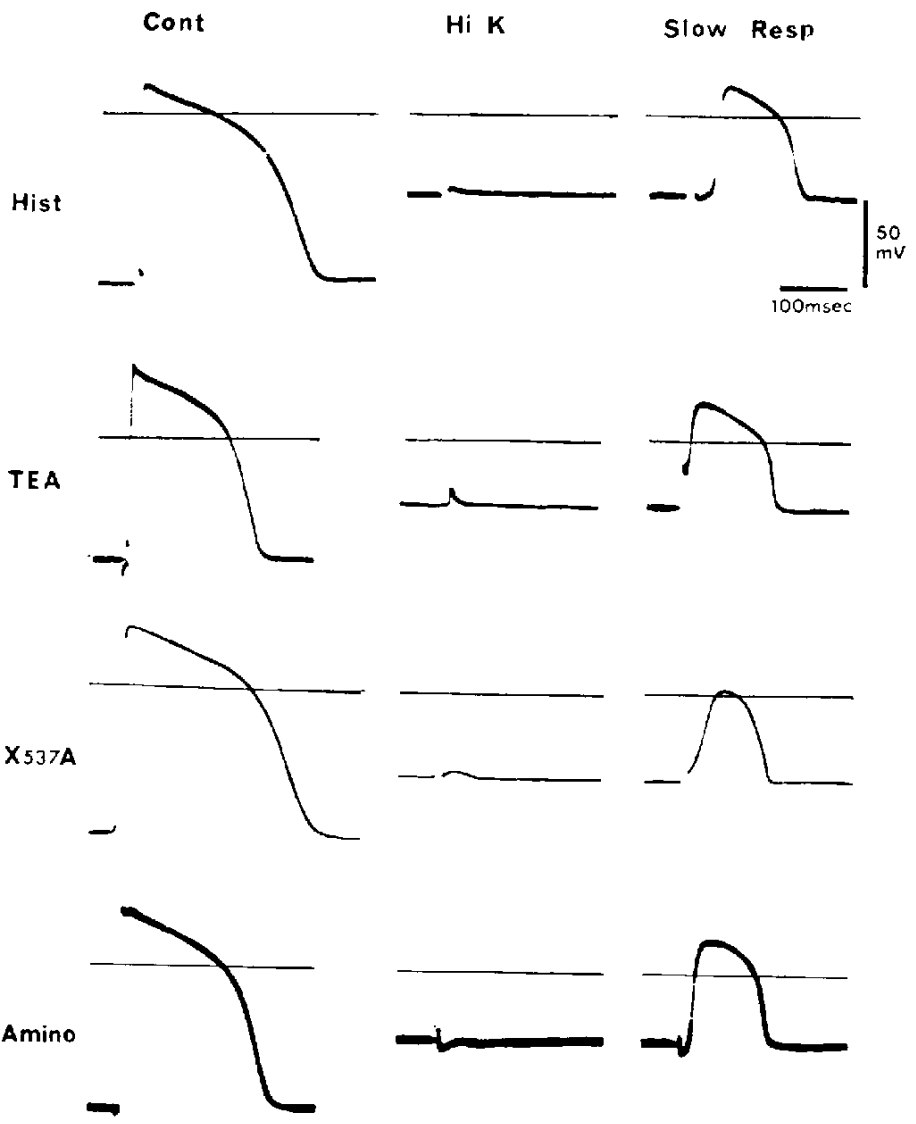

Fig. 2. Restoration of electrical response by various agents in the papillary muscles partially depolarized by $30 \mathrm{mM}$ potassium. The left records in each row are the control action potentials. The middle records in each row represent loss of electrical activity produced by the elevation of external potassium to $30 \mathrm{mM}$. The right records in each row are the slow responses induced by histamine $\left(3 \times 10^{-5} \mathrm{M}\right)$, TEA $(20 \mathrm{mM}), X-537 \mathrm{~A}\left(1.5 \times 10^{-5} \mathrm{M}\right)$ and aminophylline $(3 \mathrm{mM})$. The horizontal line represents the zero potential level. Time and voltage calibrations in the top row apply to all panels. 
A

A
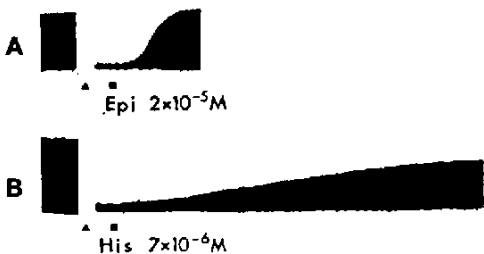

c

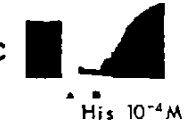

D

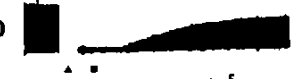

$\mathrm{X}-537 \mathrm{~A} \quad 1.5 \times 10^{-5} \mathrm{M}$

$\mathbf{E}$
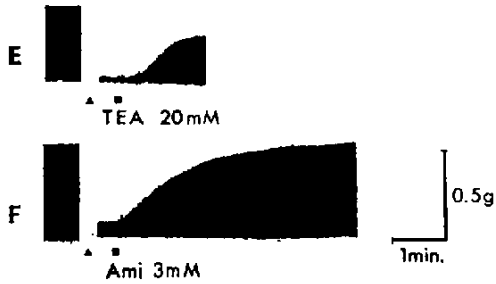

Fig. 3. Restoration by various agents of the mechanical response in the guinea pig papillary muscles partially depolarized by $30 \mathrm{mM}$ potas sium. The left records in each row are the control contractions. External potassium concentrations were increased at $\boldsymbol{A}$. and the agents were added at $\square$. Force and time calibrations apply to all panels.

response. Under such conditions, all the agonists tested were capable of restoring the mechanical response. Typical records showing the restoration of the contraction produced by several agents are shown in Fig. 3. The concentrations of these agents were $80-100 \%$ of those which produced the maximum positive inotropic effects under the normal condition: $2 \times 10^{-5} \mathrm{M}$ for epinephrine, $7 \times 10^{-6}-10^{-4} \mathrm{M}$ for histamine, $1.5 \times 10^{-5} \mathrm{M}$ for X-537A, $3 \mathrm{mM}$ for aminophylline, $20 \mathrm{mM}$ for TEA, $5 \times 10^{-5} \mathrm{M}$ for dopamine, and $3 \times 10^{-5} \mathrm{M}$ for tyramine. The force of the restored contraction by these agents was $70-130 \%$ of that seen in the case of the control contraction (Fig. 4). The force of the restored contraction produced by $20 \mathrm{mM}$ TEA, $2 \times 10^{-4} \mathrm{M}$ metanephrine, and $2 \times 10^{-4} \mathrm{M}$ serotonin $(5-\mathrm{HT})$ was $30-60 \%$ of that seen in the case of the control contraction (Fig. 4).

The restored contractions produced by histamine, TEA, X-537A, epinephrine and aminophylline remained sustained for a considerable period. The gradual decline of the restored contraction after reaching its maximum is shown in Fig. 5. The decline was the most rapid in the case of histamine $\left(10^{-4} \mathrm{M}\right)$ and slowest in the case of $X-537 \mathrm{~A}$; histamine- and $\mathrm{X}-537 \mathrm{~A}$-induced contractions decreased to $59.2 \%$ and $83.1 \%$ of the maximum force, respectively, at the 5 th min. Chelation of external $\mathrm{Ca}^{2+}$ by EGTA, $1 \mathrm{mM}$ $\mathrm{Mn}^{2+}$ and verapamil depressed the restored contraction. Typical records showing the depression by these agents of the restored contraction produced by histamine are shown in Fig. 6.

\section{DISCUSSION}

It is well established that the slow channels which transmit predominantly calcium ions through the cell membrane are present in myocardial cells and that the channel is directly or indirectly involved in the activation of the cardiac contractile machinery. Agents showing positive inotropic actions are expected to increase more or less the calcium inflow passing through these slow channels. However, it is difficult to detect the changes in the density of the slow channels by observing the shape of the normal action potential. The use of the myocardial preparation in which the excitability is abolished by tetrodotoxin or elevated levels of potassium is a simple and useful method to determine whether application of certain agents will increase the density of the slow channels. For example, catecholamines only slightly modify the shape of the normal action potential, whereas these amines elicit huge responses when the fast channels are inactivated. Thus, using this type of preparation one can readily see the effect of catecholamines in the production of slow cation 


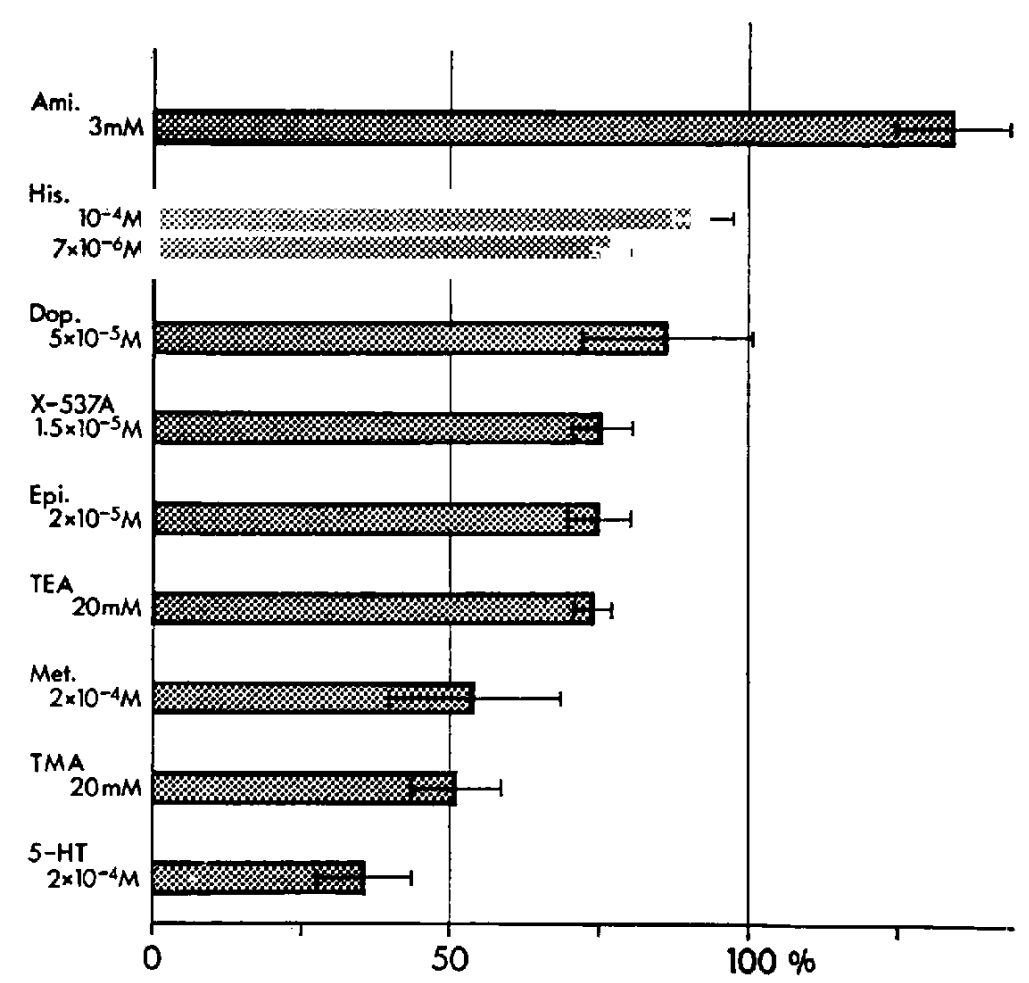

Fig. 4. Relative activity of various agents required to restore the mechanical responses in the guinea pig papillary muscle partially depolarized by $30 \mathrm{mM}$ potassium. Abscissa: restored contraction as expressed by $\%$ of the control contractions in the normal PSS. Bars at the top of each column represent standard errors. Numbers of the experiments are 29 for aminophyline, 54 for histamine $\left(10^{-4} \mathrm{M}\right), 44$ for histamine $\left(7 \times 10^{-6} \mathrm{M}\right), 4$ for dopamine, 37 for $X-537 \mathrm{~A}, 27$ for epinephrine, 50 for TEA, 4 for metanephrine, 4 for TMA, and 5 for serotonin ( $5-\mathrm{HT})$.

channels. In the present study, all of the inotropic agents tested were clearly shown to produce electrical and mechanical responses in the myocardium in which the fast sodium channels were inactivated by elevated levels of potassium. Therefore, it can be concluded at the outset that all of the inotropic agents tested did increase the density of slow channels, which does contribute at least to some extent to their positive inotropic effects.

It is difficult to evaluate quantitatively the activities of various agents which induce the slow channels by comparing the electrical responses. However, the comparison was possible to some extent by using the restored mechanical responses in the myocardium made inexcitable by depolarizing the membrane. Figure 4 shows the forces of the restored contractions produced by various agents at the concentrations which produced almost the maximum inotropic action under control conditions. When comparing Fig. 4 with Fig. 1, it can be seen that the potency of the positive inotropic action is considerably different from that required to produce the restored contraction in the depolarized muscle. In the normal cardiac muscle, the greatest increase in the contractile force was achieved with histamine, followed by epinephrine, dopamine and TEA; the maximum increase by aminophylline and $\mathrm{X}-537 \mathrm{~A}$ were relatively small. In contrast, the restored contraction produced by aminophylline in the depolarized 

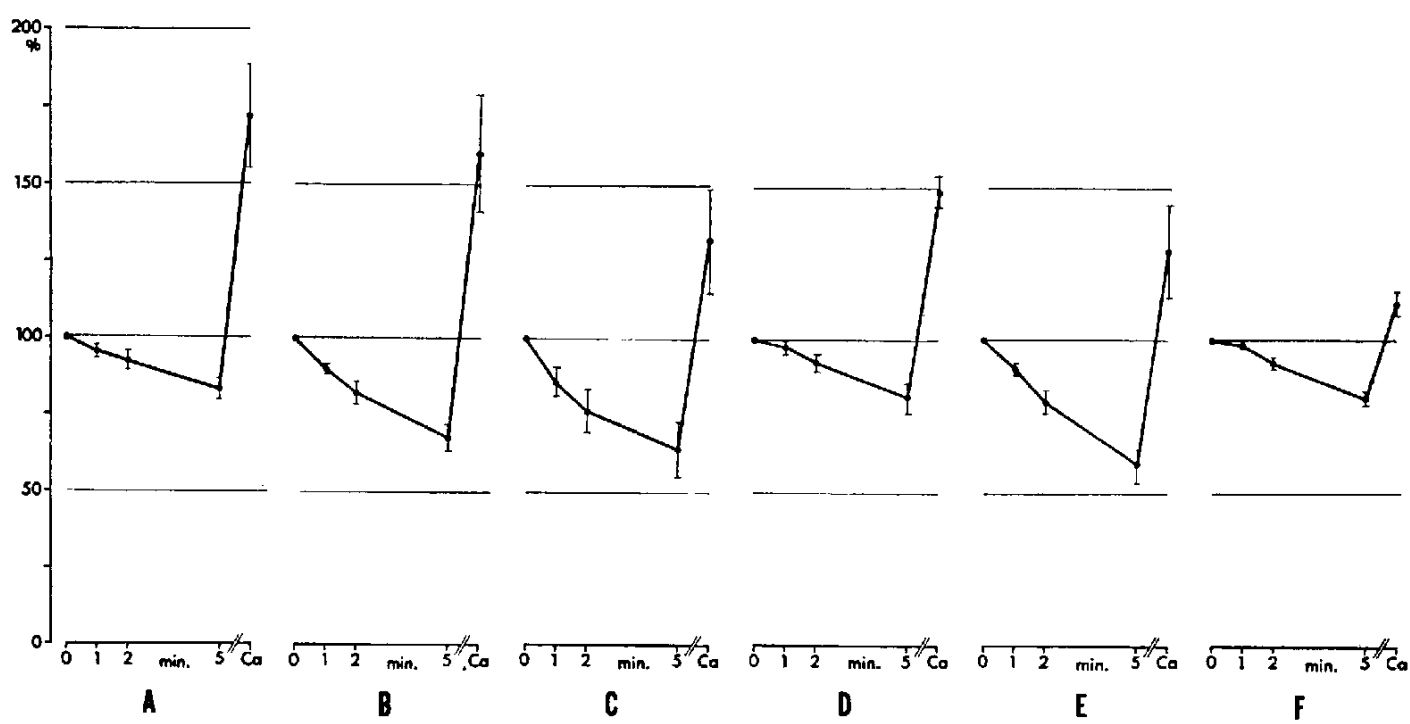

Fig. 5. Time course of the decline in the restored contractions by various agents after reaching their maximum. Abscissa: time ( $\mathrm{min}$ ) after the maximum restored contraction. At $5 \mathrm{~min}, 2 \mathrm{mM} \mathrm{Ca}{ }^{2+}$ was added. Ordinate: contractile force as expressed by $\%$ of the maximum force. Vertical bars are the standard errors from more than 5 experiments. Agents and their concentrations are: $A, X-537 \mathrm{~A}, 1.5 \times 10^{-5} \mathrm{M} ; \mathrm{B}$. TEA, $20 \mathrm{mM}$; , epinephrine, $2 \times 10^{-5} \mathrm{M} ; \mathrm{D}$, histamine, $7 \times 10^{-6} \mathrm{M} ; \mathrm{E}$, histamine, $10^{-4} \mathrm{M}: \mathrm{F}$, aminophylline, $3 \mathrm{mM}$.

muscle was the largest, and those by histamine, dopamine, X-537A, epinephrine and TEA were much the same. Therefore. the relative potencies of the agents tested were considerably different with respect to the positive inotropic action and to the activity to produce the restored contraction. Thus, the following conclusion may be drawn. Although the increase in the density of slow channels is more or less involved in the positive inotropic effects of the cardiac stimulants, the positive inotropism is not produced solely through the mechanisms related to the slow channel system. Other mechanisms must be involved when the fast channels are functioning.

The mechanisms involved in the increase in the density of the slow channels by various agents are probably not uniform. For catecholamines and histamine, the increase in the cyclic AMP is suggested to produce an increase in the slow channel density (4-6.
9): methylxanthines also produce an increase in cyclic AMP by inhibiting phosphodiesterase In the present study, we did not determine whether TEA increases the density of the slow channels directly of indirectly by inhibiting the potassium conductance. However, TEA did produce the slow response, even if it was a secondary phenomenon resulting from the inhibition of the potassium outward current. It was suggested that the action of X-537A was due to the release of endogenous catecholamines (11, 12). However, since this agent produced a slow response in the depolarized muscles from the reserpinized animals, it is likely that this ionophore is able to act directly on the plasma membrane as an ionophore to produce an increase in the slow channel density, at least at relatively high concentrations. Detailed studies showing the direct action of $X-537 A$ have been reported elsewhere (7). 
A

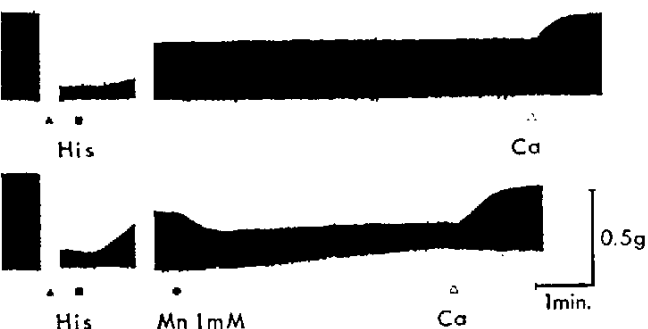

c

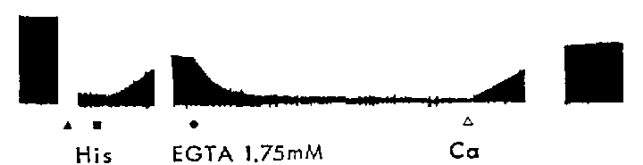

D

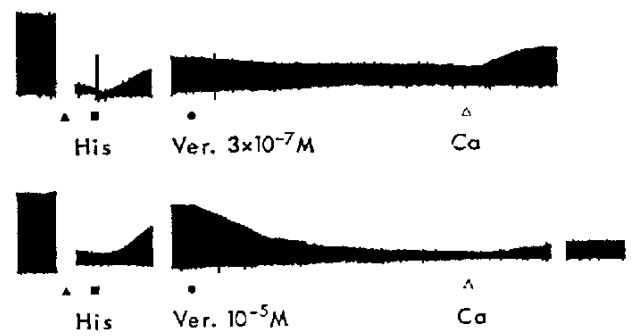

Fig. 6. Effects of the agents known to inhibit $\mathrm{Ca}^{2+}$ currents and the reduction of $\left[\mathrm{Ca}^{++}\right]_{0}$ by EGTA on the histamine-induced restored contraction in the depolarized guinea pig papillary muscle. $\left[\mathrm{K}^{+}\right]_{0}$ was increased to $30 \mathrm{mM}$ at $\mathbf{\Delta}$ and histamine $\left(7 \times 10^{-6} \mathrm{M}\right)$ was added at $\mathbf{D}$. After obtaining the maximum contraction, $\mathrm{Mn}$, EGTA, and verapamil were added. All of the agents depressed the histamine-induced restored contraction and the depression was partially recovered by the addition of $2 \mathrm{mM}$ $\mathrm{Ca}^{2+}$. Calibrations in $\mathrm{B}$ apply to all panels.

\section{REFERENCES}

1) Reuter, H. and Beeler, Jr., G.W.: Calcium current activation of contraction in ventricular myocardial fibers. Science 163, 399-401 (1969)

2) New, W. and Trautwein, W: Inward membrane currents in mammalian myocardium. Pflügers Arch. 334, 1-23 (1972)

3) New, W. and Trautwein, W.: The ionic nature of slow inward current and its relation to contraction. Pflügers Arch. 334, 24-38 (1972)

4) Shigenobu, K. and Sperelakis, N.: Calcium current channels induced by catecholamines in chick embryonic hearts whose fast sodium channels are blocked by tetrodotoxin or elevated potassium. Circulation Res. 31, 932-952 (1972)

5) Schneider, J.A. and Sperelakis, N.: The demonstration of energy dependence of the isoproterenol-induced transcellular $\mathrm{Ca}^{2+}$ current in isolated perfused guinea pig hearts-an explanation for mechanical failure of ischemic myocardium. J. Surg. Res. 16, 389-403 (1974)

6) Schneider, J.A. and Sperelakis, N.: Slow Ca ${ }^{2+}$ and $\mathrm{Na}^{+}$responses induced by isoproterenol and methylxanthines in isolated perfused guinea pig hearts exposed to elevated $\mathrm{K}^{+}$. J. Mol. Cell. Cardiol. 7, 249-273 (1975)

7) Shigenobu, K., Tatsuno, $H$. and Kasuya, $Y$.: Evidence for a direct action of $X-537 \mathrm{~A}$ on the cardiac plasma membrane as an ionophore. J. Pharm.-Dyn. 1, 1-7 (1978)

8) Shigenobu, K., Tatsuno, H., Matsuki, N., Oshima, T. and Kasuya, Y.: Electrophysiological and mechanical studies on the cardiac effects of a histamine $\mathrm{H}_{2}$ receptor antagonist. cimetidine, in the isolated guinea pig myocardium. J. Pharm.-Dyn. 2, 141-150 (1979)

9) Josephson, I., Renaud, J.-R., Vogel, M., McLean, M. and Sperelakis, N.: Mechanism of the histamine-induced positive inotropic action in cardiac muscle. Europ. J. Pharmacol. 35, 393-398 (1976)

10) Inui, J. and Imamura, H.: Restoration by histamine of the calcium-dependent electrical and mechanical response in the guinea pig papillary muscle partially depolarized by potassium. Arch. Pharmacol. 294, 261-269 (1976)

11) Levy, J.V., Cohen, I.A. and Inesi, G.: Contractile effects of a calcium ionophore. Nature 242, $461-463$ (1973)

12) Schaffer, S.W., Safer, B., Scarpa, A. and Williamson, J.R.: Mode of action of the calcium ionophores X-537A and A23187 on cardiac contractility. Biochem. Pharmacol. 23, 16091617 (1974) 